\begin{tabular}{ccc}
\hline & International Journal of Physical Research, $8(1)(2020) 8-13$ \\
SPC & International Journal of Physical Research \\
Website $:$ www.sciencepubco.com/index.php/IJPR & Research paper \\
\hline
\end{tabular}

\title{
Structural and elastic properties, Vickers hardness and Debye temperature of (B1) BP: DFT study
}

\author{
Salah Daoud* \\ Laboratory of Materials and Electronic Systems (LMSE), Faculty of Sciences and Technology, Mohamed Elbachir El Ibrahimi Bordj \\ Bou Arreridj University, 34000 Bordj Bou Arreridj, Algeria \\ *Corresponding authorE-mail:salah_daoud07@yahoo.fr
}

\begin{abstract}
A theoretical study of the structural parameters and elastic constants of boron phosphide (BP) compound with cubic rocksalt structure has been carried out using ab-initio density functional theory (DFT) and density functional perturbation theory (DFPT) calculations based on the plane-wave and pseudopotential (PW-PP) approach. Elastic anisotropy factors, Cauchy pressure, inverted Pugh's ratio, aggregate mechanical moduli (shear modulus, Young's modulus and Poisson's ratio), Vickers hardness Hv, elastic wave velocity as well as the Debye temperature $\theta_{\mathrm{D}}$ and the melting point have been also calculated. Our obtained results are in general in good agreement with other data of the literature. The deviation between our obtained value (4.225 $\AA$ ) of the lattice constant and the theoretical value (4.282 $\AA$ ) of the literature is around $1.33 \%$, while that between our obtained value $(169.7 \mathrm{GPa})$ of the bulk modulus and the theoretical one (171 $\mathrm{GPa}$ ) is only around $0.77 \%$. The calculated values of $\mathrm{HV}$ and $\theta_{\mathrm{D}}$ were found at around $30.5 \mathrm{GPa}$ and $1254 \mathrm{~K}(1314.4 \mathrm{~K})$, respectively.
\end{abstract}

Keywords: Density Functional Theory; Boron Phosphide; Structural Parameters; Elastic Constants; Vickers Hardness; Debye Temperature.

\section{Introduction}

Recently, group III-V semiconducting compounds have attracted a great deal of attention [1-13] anticipating fabrication of important electronic devices [1]. Among III-V semiconducting compounds, boron phosphide (BP) is classified as a refractory material. Electronically, boron phosphide has resemblance with silicon carbide $(\mathrm{SiC})$ semiconducting compound. Like boron arsenide (BAs) and boron antimonide (BSb) semiconducting materials, BP shows also a strong covalent nature and exhibits an unusual behavior due to small core and absence of $\mathrm{p}$ electrons in the core of boron atom compared to some other III-V semiconducting compounds [1].

El Haj Hassan et al. [2] have studied the structural parameters, the elastic constants and electronic properties of cubic zinc-blende boron based compounds (including BP semiconducting material) using the full-potential augmented plane-wave (FP-LAPW) method. They are also investigated the elastic constants of cubic rock-salt phase of BN, BP, BAs and BSb binary materials. In addition, they discussed the bonding parameter in terms of charge density, which suggests that the bonding of BP, BAs and BSb are less ionic than in other zincblende compounds (BN, GaN, AlN...etc). They found also that BP semiconducting material transforms from the zinc-blende (B3) phase to rock-salt (B1) one at pressure $128 \mathrm{GPa}$; while Arbouche et al. [5] found that the first order transition is from B3 phase to NiAs at pressure of around $133.26 \mathrm{GPa}$.

Varshney et al. [9] have investigated the structural phase transition under high pressure, elastic constants and thermodynamical properties of some III-V (BN, BP, and BAs) semiconducting compounds in cubic zincblende and rock-salt phases by formulating an effective interionic interaction potential. They found that BP transforms from the (B3) structure to (B1) phase at pressure of $160 \mathrm{GPa}$, while the pressure of the transformation in BAs was found at around $110 \mathrm{GPa}$.

More recently, in our previous work [13], the structural parameters and the elastic constants of cubic rock-salt phase BP material were investigated using plane wave-pseudopotential (PW-PP) approach in the framework of the density functional theory (DFT) and the density functional perturbation theory (DFPT) with the generalized gradient approximation (GGA). We are also investigated the sound velocity, the Debye temperature as well as the melting temperature.

Elastic constants of materials are fundamental and indispensable to describe their mechanical properties. They are used to determine several aggregate mechanical moduli, especially: the bulk modulus B, Young's modulus E, shear modulus G, Poisson's ratio v, elastic anisotropy factor, and Cauchy pressure of materials. These aggregate mechanical moduli are usually used also to investigate the elastic wave speed, the Debye temperature and sometimes the melting point. It is very obvious that the elastic constants play an important role in determining the strength of the materials [14]. Furthermore, Pugh [15] has introduced the ratio between the shear modulus and the bulk modulus (G/B) to distinguish the ductile/brittle behaviors of aggregate polycrystalline pure metals. A high (low) G/B value is correlated with the brittleness (ductility) of the pure metals.

In the present work, we compute the structural parameters, the elastic constants and some other physical quantities of B1-BP material using the PP-PW approach with the local density approximation (LDA) in the framework of the DFT and the DFPT. 


\section{Computational method}

The structural parameters and the elastic constants calculated here were carried out using ABINIT computer code [16]. This software is based on the PP-PW approach in the framework of the DFT and the DFPT. The Troullier-Martins type pseudopotentials [17], which have been generated thanks to the FHI98PP code [18] were used to describe the interactions between the valence electrons and the nuclei and core electrons, while the exchange-correlation energy term was evaluated using the local density approximation (LDA) [19]. The total energy $E_{\text {tot }}$ was found converged near the energy cutoff of 80 Hartree (figure 1(a)). The Brillouin zone was sampled by $12 \times 12 x 12$ (corresponding to $280 \mathrm{nkpt}$, as shown in figure 1(b)) Monkhorst and Pack mesh of k-points [20]. Careful convergence tests show that with these two optimal values, the relative energy is converged to better than $10^{-6}$ Hartree.

(A)

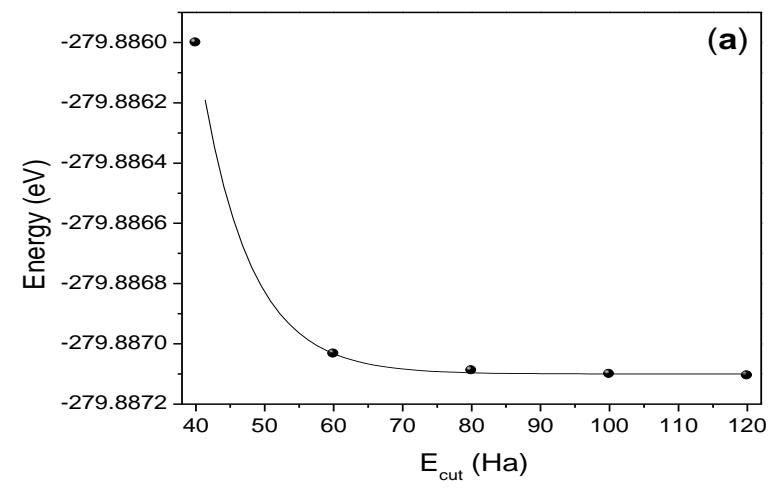

(B)

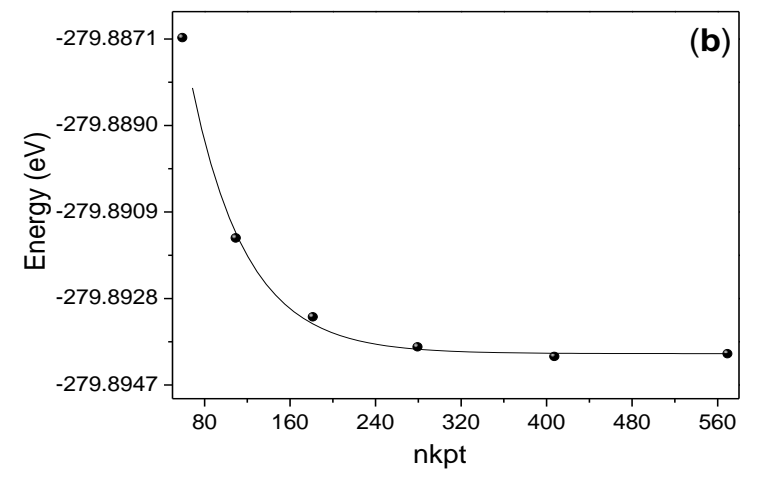

Fig. 1: Scatter Plot of Data, Plus Exponential Fitted Straight Line of $E_{\text {tot }}$ versus Energy Cutoff and Number of K-Points of BP Compound with B1 Phase.

\section{Results and discussions}

\section{1. Equilibrium structural parameters}

To obtain the static properties of boron phosphide (BP) in cubic rock-salt (B1) phase, we calculated the total energies at about eight different volumes and fitted them with an equation of state. The obtained total energies of boron phosphide in (B1) phase are plotted for different Wigner-Seitz volumes in figure 2. The choice of the equation of state, in particular the Murnaghan or Birch equations does not change the calculated structural properties within the desired accuracy [21]. Therefore, only Murnaghan's equation of state is usually employed; it is expressed as follow [6]:

$$
E(V)-E\left(V_{0}\right)=\frac{B_{0} V}{B_{0}^{\prime}}\left[\frac{\left(V_{0} / V\right)^{B_{0}^{\prime}}}{B_{0}^{\prime}-1}+1\right]-{\frac{B_{0} V_{0}^{\prime}}{B_{0}^{\prime}-1}}^{(1)}
$$

Where $\mathrm{B}_{0}$ is the bulk modulus (considering as the resistance to fracture) given at $\mathrm{P}=0, \mathrm{~V}_{0}$ is the equilibrium cell volume, $\mathrm{E}\left(\mathrm{V}_{0}\right)$ is the energy corresponding to equilibrium cell volume, and $\mathrm{B}_{0}{ }^{\prime}$ is the pressure derivative of the bulk modulus.

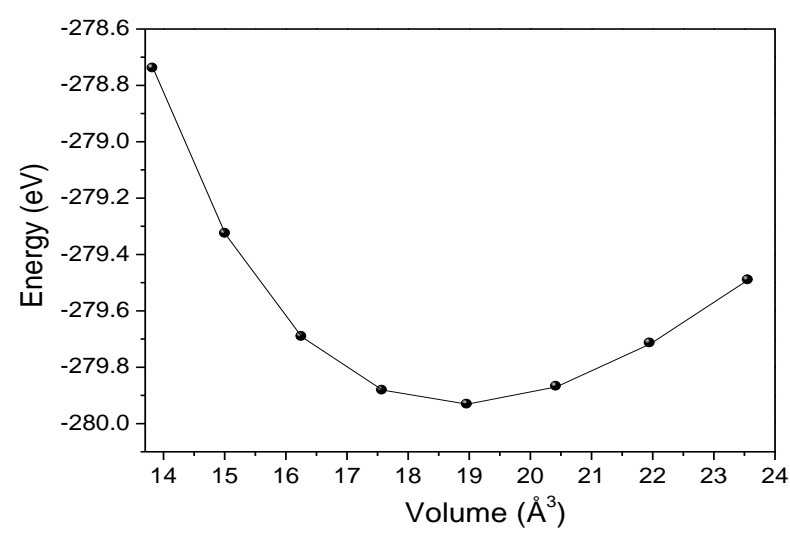

Fig. 2: Total Energy Variation with the Unit Cell Volume of Rock-Salt (B1) Phase of BP Compound.

The obtained equilibrium values of $\mathrm{a} 0, \mathrm{~B}_{0}$, and $\mathrm{B}_{0}{ }^{\prime}$ are given in Table 1, and compared with other theoretical data [4], [5], [8] and [13]. In general, our calculated values of $\mathrm{a} 0, \mathrm{~B}_{0}$ and $\mathrm{B}_{0}{ }^{\prime}$ are agreed with other theoretical data [4], [5], [8] and [13]. The deviation between our calculation $(169.7 \mathrm{GPa})$ of $\mathrm{B}_{0}$ and the theoretical one $(171 \mathrm{GPa})$ reported by El Haj Hassan et al. [2] is only about $0.77 \%$. It can be seen that our value (3.82) of $\mathrm{B}_{0}{ }^{\prime}$ is slightly higher than the previous theoretical results 3.32 (3.6) and 3.58 reported by Meradji et al. [4], and Arbouche et al. [8], respectively, and slightly lower than our previous value 4.64. So our present value (3.82) of $\mathrm{B}_{0}{ }^{\prime}$ is localized between these different theoretical data. 
Table 1: Equilibrium Lattice Constant $\mathrm{A}_{0}$, Bulk Modulus $\mathrm{B}_{0}$, and Its Pressure Derivatives $\mathrm{B}_{0}$ 'of BP With Rock-Salt Structure, Compared to Other Theoretical Data of the Literature., ${ }^{\mathrm{a}} \mathrm{LDA},{ }^{\mathrm{b}} \mathrm{GGA},{ }^{\mathrm{c}} \mathrm{PP}-\mathrm{PW},{ }^{\mathrm{d}} \mathrm{LMTO}$

\begin{tabular}{|c|c|c|c|}
\hline Parameter & $a_{0}(\AA)$ & $\mathrm{B}_{0}(\mathrm{GPa})$ & $\mathrm{B}_{0}^{\prime}$ \\
\hline This work & 4.225 & 169.7 & 3.82 \\
\hline Ref. [4] ${ }^{\mathrm{a}}$ & 4.268 & 177 & 3.32 \\
\hline Ref. $[4]^{b}$ & 4.332 & 161 & 3.60 \\
\hline Ref. [5] ${ }^{b}$ & 4.32 & 177.2 & 3.58 \\
\hline Ref. $[8]^{c}$ & 4.30 & 152 & - \\
\hline Ref. $[8]^{\mathrm{d}}$ & 4.27 & 176 & - \\
\hline Ref. [13] ${ }^{b}$ & 4.282 & 148.4 & 4.64 \\
\hline
\end{tabular}

There are several different ways to estimate the melting point $\mathrm{T}_{\mathrm{m}}$ of material. For materials with cubic structure (cubic primitive (cP), cubic close packed (CCP), face-centered cubic (FCC),...etc), the melting point $\mathrm{T}_{\mathrm{m}}$ correlates with the bulk modulus $\mathrm{B}$ as follow [22]: $\mathrm{T}_{\mathrm{m}}=607+9.3 \mathrm{~B}$, where the bulk modulus $\mathrm{B}$ is expressed in GPa, while the melting point $\mathrm{T}_{\mathrm{m}}$ is expressed in $\mathrm{K}$. Replacing our value $(169.7 \mathrm{GPa})$ of the bulk modulus $\mathrm{B}$ in the previous expression, the melting point $\mathrm{T}_{\mathrm{m}}$ of B1-BP was theoretically estimated at around $2185.2 \mathrm{~K}$, which is slightly lower than the theoretical value $2482 \pm 300 \mathrm{~K}$ obtained from the elastic constant $\mathrm{C}_{11}$ reported in our previous work [13].

In the following part, we therefore concentrate on the bulk modulus, and the normalized volume $\left(\mathrm{V}_{\mathrm{p}} / \mathrm{V}_{0}\right)$ of $\mathrm{B} 1-\mathrm{BP}$ under pressure. The bulk modulus $\mathrm{B}$ is defined as the derivative of pressure $\mathrm{P}$ with respect to volume $\mathrm{V}$, it is given by the following expressions [21]

$$
B(P)=-V(\partial P / \partial V)=V\left(\partial^{2} E / \partial V^{2}\right)(2)
$$

Usually under the application of large hydrostatic pressure, the concept of the nonlinear terms in elastic properties is used, but for many technological applications, it is sufficient to consider only the linear terms, the bulk modulus can be approximately given as follow [21] $: \mathrm{B}(\mathrm{P}) \approx \mathrm{B}_{0}+\mathrm{B}_{0}{ }^{\prime} \mathrm{P}$. So, the pressure dependence of the bulk modulus $\mathrm{B}$ of $\mathrm{BP}$ in $\mathrm{B} 1$ phase, it is given by the following expression: $\mathrm{B}(\mathrm{P})=$ $169.7+3.82 \mathrm{P}$. The variations of the bulk modulus $\mathrm{B}(\mathrm{P})$ of $\mathrm{B} 1-\mathrm{BP}$ compound versus the pressure $\mathrm{P}$ are plotted in figure 3 .

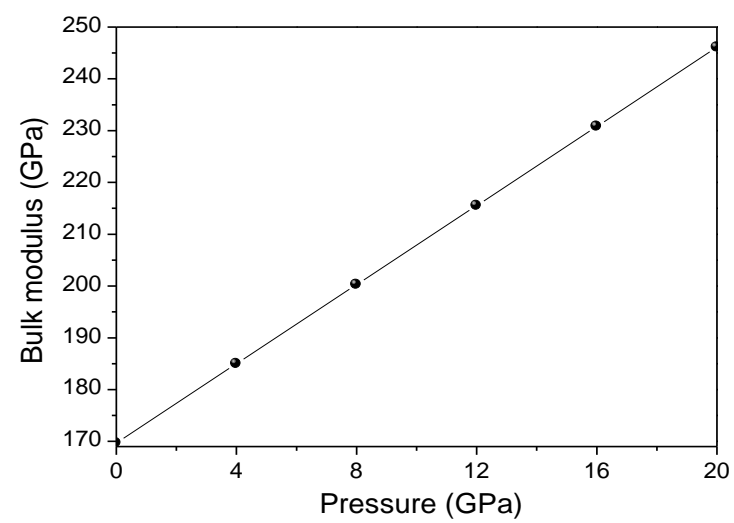

Fig. 3: Bulk Modulus Variation with the Hydrostatic Pressure of BP Compound with Rock-Salt Phase.

Under compression, several models were proposed to relate the pressure and the volume (P-V) data. First one the third-order Vinet EOS, which is expressed as follow [13]

$$
P=3 B_{0}\left(\frac{1-f_{V}}{f_{V}^{2}}\right) \exp \left[\frac{3}{2}\left(B^{\prime}{ }_{0}-1\right)\left(1-f_{V}\right)\right](3)
$$

Where $\mathrm{B}_{0}$ is the bulk modulus, $\mathrm{B}_{0}{ }^{\prime}$ is the pressure derivative of the bulk modulus, $\mathrm{f}_{\mathrm{V}}$ is expressed as follow: $\mathrm{f}_{\mathrm{V}}=\sqrt[3]{\mathrm{V} / \mathrm{V}_{0}}, V_{0}$ is the volume at zero-pressure (the equilibrium volume), and $\mathrm{V}$ is the volume at pressure $\mathrm{P}$, respectively.

The changes of the pressure $P$ can be obtained through the volumes using to the following expression [6]

$$
P(V)=\left(B_{0} / B_{0}^{\prime}\right)\left(\left(V_{0} / V\right)^{B_{0}^{\prime}}-1\right)(4)
$$

Reciprocally to Eq. (4), the normalized volume $\left(\mathrm{V}_{\mathrm{p}} / \mathrm{V}_{0}\right)$ can be written as a function of pressure $\mathrm{P}$ as follow:

$$
\mathrm{V} / \mathrm{V}_{0}=\left(1+\left(\mathrm{B}_{0}^{\prime} / \mathrm{B}_{0}\right) \mathrm{P}\right)^{-1 / \mathrm{B}^{\prime}}{ }_{0}(5)
$$

Replacing our obtained values of the equilibrium volume $\mathrm{V}_{0}$, the bulk modulus $\mathrm{B}_{0}$ and the pressure derivative of the bulk modulus $\mathrm{B}_{0}{ }^{\prime}$ in Eq. (5), the values of the normalized volume $\left(\mathrm{V}_{\mathrm{p}} / \mathrm{V}_{0}\right)$ versus pressure $\mathrm{P}$ are calculated. Aiming to compare the compressibility behavior, a comparison of the results obtained here, along with the theoretical ones reported by Arbouche et al. [5], and our previous work [13] using the GGA are plotted in Fig. 4. From curves of figure 4, we observe clearly that $\mathrm{V}_{\mathrm{p}} / \mathrm{V}_{0}$ of BP compound with rock-salt phase decreases with increasing of pressure. It is started with the value 1 at zero pressure, and it reaches the value of around 0.734 at $100 \mathrm{GPa}$, which is slightly higher than the theoretical ones 0.704 and 0.716 reported by Arbouche et al. [5], and our previous work [13], respectively. 


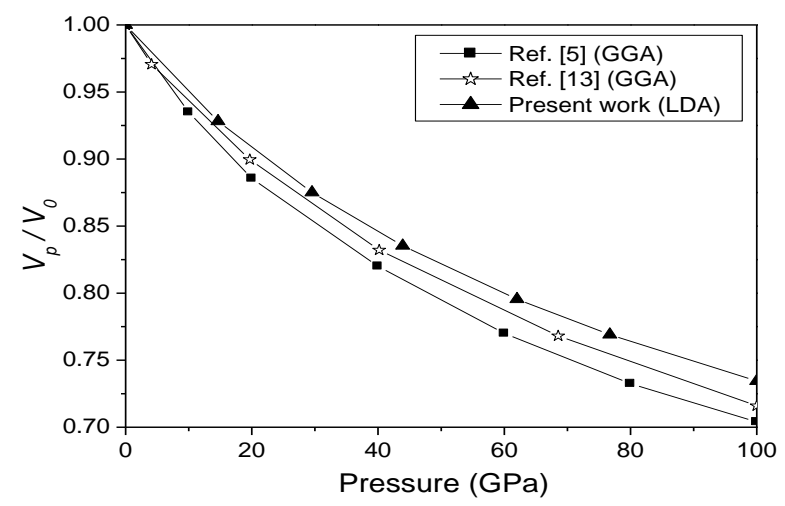

Fig. 4: Normalized Volume $\left(\mathrm{V}_{\mathrm{p}} / \mathrm{V}_{0}\right)$ Versus Pressure for BP Compound with Rock-Salt Phase.

\subsection{Elastic constants and related parameters}

The elastic constants of materials are of interest, because they give information on the nature of the binding forces in solids. They are also used to predict some thermal properties of solids (such as the Debye temperature $\theta_{\mathrm{D}}$ and the melting temperature $\mathrm{T}_{\mathrm{m}}$ ).For crystals with cubic structures, only three elastic constants are distinguished $\left(C_{11}, C_{12}\right.$ and $\left.C_{44}\right)$ [23-27]. The elastic constants were obtained here using the DFPT. For more detail on the calculation of the elastic constants using the DFPT, please see for example our previous works [13], [26]. The obtained values of $\mathrm{C}_{11}, \mathrm{C}_{12}$ and $\mathrm{C}_{44}$ for $\mathrm{BP}$ material with $\mathrm{B} 1$ phase are given in Table 2, and compared with other theoretical data [2] and [13]. For a three-dimensional cubic solid the stability conditions can be expressed in terms of the elastic stiffness coefficients of the substance as: $\mathrm{C}_{11}+2 \mathrm{C}_{12}>0 \mathrm{C}_{44}>0, \mathrm{C}_{11}-\mathrm{C}_{12}>0$ [28]. The elastic constants at zero pressure of BP material with B1 phase obey these mechanical stability conditions, including that $\mathrm{C}_{11}$ must be higher than $\mathrm{C}_{12}$.

It is observed that our obtained values of $\mathrm{C}_{11}$ and $\mathrm{C}_{44}$ are slightly higher than the previous theoretical results reported by El Haj Hassan et al. [2], and Daoud [13], while our obtained value of $\mathrm{C}_{12}$ is slightly lower than the previous theoretical results reported in Refs. [2], [13]. Except the data reported in Refs. [2], [13], to the best of my knowledge, there are no other data available in the literature on the elastic constants for BP compound with B1 phase. In cubic crystals, the bulk modulus B and the isotropic shear modulus G are expressed as a function of the elastic constants $\mathrm{C}_{\mathrm{ij}}$ as follows [26]:

$$
\mathrm{B}=\left[\left(\mathrm{C}_{11}+2 \mathrm{C}_{12}\right) / 3\right] \text {, and } \mathrm{G}=\left(\mathrm{Gv}+\mathrm{G}_{\mathrm{R}}\right) / 2 \text {, where } \mathrm{Gv}=\left(\mathrm{C}_{11}-\mathrm{C}_{12}+3 \mathrm{C}_{44}\right) / 5 \text {, and }\left(5 / \mathrm{G}_{\mathrm{R}}\right)=\left[\left(4 /\left(\mathrm{C}_{11}-\mathrm{C}_{12}\right)\right)+\left(3 / \mathrm{C}_{44}\right)\right](6)
$$

Our calculated values of B and G are given in Table 2, along with other theoretical data [2], and [13]. In cubic crystals, the elastic anisotropy factor S and the Zener anisotropy factor A are usually used to describe the degree of the elastic anisotropy in materials [27]. They are given as a function of the elastic constants $C_{i j}$ as follows [27]

$$
\mathrm{S}=\left[1 /\left(\mathrm{C}_{11}-\mathrm{C}_{12}\right)\right]-\left[1 /\left(2 \mathrm{C}_{44}\right)\right], \text { and } \mathrm{A}=\left[2 \mathrm{C}_{44} /\left(\mathrm{C}_{11}-\mathrm{C}_{12}\right)\right]=\mathrm{C}_{44} / \mathrm{C}^{\prime}(7)
$$

Where $C^{\prime}=\left(\mathrm{C}_{11}-\mathrm{C}_{12}\right) / 2$ is the tetragonal shear modulus.

Our calculated values of $\mathrm{C}^{\prime}, \mathrm{S}$ and A of single crystal BP with $\mathrm{B} 1$ phase are: $190.5 \mathrm{GPa}, 0.09 \times 10^{-2} \mathrm{GPa}^{-1}$ and 1.54 , respectively. Our calculated values of S and A are given in Table 2. The calculated S and A indicate that BP with B1 phase is elastically anisotropic. To the best of our knowledge, there are no other data available in the literature on the $\mathrm{S}$ and A for single crystal BP with B1 phase.

The Cauchy pressure $C_{p}\left(C_{p}=C_{12}-C_{44}\right)$ and the inverted Pugh's ratio $\left(k^{-1}=B / G\right.$, where $B$ is the bulk modulus and $G$ is the isotropic shear modulus) are two indicators of ductility of materials, they are often used to evaluate the ductile-brittle nature of materials. The negative value of $C_{p}$ implies the brittle manner of a compound, while the positive value of $C_{p}$ implies the ductile behavior. In other hand,material having small inverted Pugh's ratio implies its tendency to the brittleness, while for large inverted Pugh's inverted; the material tends to be ductile [27]. The Cauchy pressure $C_{p}$ and inverted Pugh's ratio $\left(\mathrm{k}^{-1}=\mathrm{B} / \mathrm{G}\right)$ of BP with B1 phase are estimated at around $-248 \mathrm{GPa}$ and 0.70 , respectively. They are also summarized in Table 2 . The values of the Cauchy pressure and the B/G ratio show a brittle manner for the BP with B1 phase.

The Young modulus E and the Poisson's ratio $\sigma$ are usually expressed as function of the bulk modulus B and the isotropic shear modulus $\mathrm{G}$ as follow [13]: $\mathrm{E}=9 \mathrm{BG} /(3 \mathrm{~B}+\mathrm{G})$, and $\sigma=(3 \mathrm{~B}-2 \mathrm{G}) /(6 \mathrm{~B}+2 \mathrm{G})$. Our calculated values of $\mathrm{E}$ and $\sigma$ of BP aggregate polycrystalline material are $502.14 \mathrm{GPa}$ and 0.02 , respectively. They are also summarized in Table 2, along the results obtained in Ref. [13].

Table 2:Elastic Constants $\mathrm{C}_{\mathrm{ij}}$ (in GPa), Bulk Modulus B (in GPa), Shear Modulus G (in GPa), Tetragonal Shear Modulus C' (in GPa), Inverted Pugh's Ratio (B/G), Young's Modulus E (in GPa), Elastic Anisotropy Factor S (in $10^{-2} \mathrm{GPa}^{-1}$ ), Zener Anisotropy Factor A, Cauchy Pressure $\mathrm{C}_{\mathrm{p}}$ (in GPa), and

\begin{tabular}{|c|c|c|c|c|c|c|c|c|c|c|c|c|}
\hline Parameter & $\mathrm{C}_{11}$ & $\mathrm{C}_{12}$ & $\mathrm{C}_{44}$ & B & $\mathrm{G}$ & $\mathrm{C}^{\prime}$ & $\mathrm{B} / \mathrm{G}$ & $\mathrm{E}$ & $\mathrm{S}$ & $\mathrm{A}$ & $\mathrm{C}_{\mathrm{p}}$ & $\sigma$ \\
\hline This work & 427 & 46 & 294 & 173 & 247.06 & 190.5 & 0.70 & 502.14 & 0.09 & 1.54 & -248 & 0.02 \\
\hline Ref. [2] & 341 & 86 & 248 & 171 & - & - & - & - & - & - & - & - \\
\hline Ref. [13] & 326.4 & 68.2 & 274.9 & 154.25 & 202.97 & - & - & 423.26 & - & - & - & - \\
\hline
\end{tabular}
Poisson's Ratio $\sigma$ of Boron Phosphide with Rock-Salt Structure, Compared to Other Theoretical Data [2], [13]

There is considerable interest in the effect of mechanical stresses resulting from crystal growth and device processing on the behavior and reliability of semiconductor devices [29]. The direction dependence of the single crystal Young's modulus E can also used to describe the elastic anisotropy of our material of interest, it can be obtained using the following formula [27, 30],

$$
\mathrm{E}^{-1}=\mathrm{s}_{11}-\beta_{1}\left(\alpha^{2} \beta^{2}+\alpha^{2} \gamma^{2}+\beta^{2} \gamma^{2}\right)(8)
$$


Where $\alpha, \beta$, and $\gamma$ in Eq. (8) denote the direction cosines of the tensile stress direction, $s_{\mathrm{ij}}$ are the elastic compliance constants, and $\beta_{1}$ is functional of $\mathrm{s}_{\mathrm{ij}}$, it is expressed as follow [30]: $\beta_{1}=\left(2 \mathrm{~s}_{11}-2 \mathrm{~s}_{12}-\mathrm{s}_{44}\right)$. The elastic compliance constants $\mathrm{s}_{11}, \mathrm{~s}_{22}$, and $\mathrm{s}_{44}$ are related to the elastic stiffness constants $\mathrm{C}_{11}, \mathrm{C}_{22}$, and $\mathrm{C}_{44}$ as follow [29, 31]:

$$
\mathrm{s}_{11}=\left(\mathrm{C}_{11}+\mathrm{C}_{12}\right) /\left(\left(\mathrm{C}_{11}-\mathrm{C}_{12}\right) \mathrm{x}\left(\mathrm{C}_{11}+2 \mathrm{C}_{12}\right)\right), \mathrm{s}_{12}=-\mathrm{C}_{12} /\left(\left(\mathrm{C}_{11}-\mathrm{C}_{12}\right) \mathrm{x}\left(\mathrm{C}_{11}+2 \mathrm{C}_{12}\right)\right), \text { ands } 44=1 / \mathrm{C}_{44}(9)
$$

The numerical values of $\mathrm{s}_{\mathrm{ij}}$ and $\beta_{1}$ of B1-BP are: $\mathrm{s}_{11}=0.00239 \mathrm{GPa}^{-1}, \mathrm{~s}_{12}=-0.00023 \mathrm{GPa}^{-1}, \mathrm{~s}_{44}=0.0034 \mathrm{GPa}^{-1}$, and $\beta_{1}=0.00185 \mathrm{GPa}^{-1}$, respectively. The maximum and minima values of $E\left(E_{\max }\right.$ and $\left.E_{\min }\right)$ are strongly depend to the value of $\beta_{1}$. If $\beta_{1}>0$, the maximum and minima values of $E$ are expressed as: $E_{\max }=3 /\left(s_{11}+2 s_{12}+s_{44}\right)$, and $E_{\min }=1 / s_{11}$. The details of the present procedure can be found in Ref. [27]. The estimated values $E_{\max }$ and $E_{\min }$ of the Young's modulus are equal to: 563.05 and $418.05 \mathrm{GPa}$, respectively. The result of $\mathrm{E}_{\max } / \mathrm{E}_{\min }$ ratio obtained in this work for BP with rock-salt structure is around 1.35.

The Vickers hardness Hv measurement is one of the most techniques used in to characterize the solids [27]. The hardness is very sensitive to structure, dislocations and other defects existing in the solids. As mentioned in Ref. [27], many attempts have been made to correlate hardness with other physical properties for a wide range of materials. Through the empirical formula, the Vickers hardness $\mathrm{Hv}_{\mathrm{v}}$ and the Young modulus E are related by [32]: $\mathrm{Hv}=0.0607 \mathrm{E}$. Replacing our obtained value $(502.14 \mathrm{GPa})$ of E in this formula, the calculated value of the Vickers hardness $\mathrm{Hv}_{\mathrm{v}}$ of rock-salt BP is found at around $30.5 \mathrm{GPa}$. This value of $\mathrm{Hv}$ is in excellent agreement with the experimental Knoop microhardness values $32 \mathrm{GPa}$ and Vickers hardness $31 \mathrm{GPa}$ of cubic-zincblende phase reported by Adachi [29], and Brazhkin et al. [33], respectively. Unfortunately, to the best of our knowledge, there are no data available in the literature on $\mathrm{Hv}$ for BP compound with B1 structure.

\subsection{Sound velocity and Debye temperature}

In this section of the present research, we therefore concentrate on the sound velocity speeds and the Debye temperature $\theta \mathrm{D}$ of B1-BP. Usually, after predicting the elastic constants of several solids, it is possible to calculate some other related parameters such as elastic wave speed, melting point, and Debye temperature. This later is not only a direct characterization of atomic force but also closely related to the atomic interaction potential energy [34].Two types of sound waves in anisotropic materials were distinguished, longitudinal and shear (transverse) waves. These two types of sound waves can be obtained if the elastic constants and crystal density of a solid are known [23]. The longitudinal $\mathrm{vl}$, transverse $\mathrm{vt}_{\mathrm{t}}$, and average $\mathrm{vm}_{\mathrm{m}}$ sound velocities of BP compound with $\mathrm{B} 1$ structure are also calculated, the details of calculation are described in our previous work [26]. At low temperature, the Debye temperature $\theta_{\mathrm{D}}$, can be obtained from the sound velocities. For materials with cubic-zincblende phase (valuable also for materials with cubic rock-salt phase), the Debye temperature $\theta_{\mathrm{D}}$ can be obtained from the lattice parameter a (in $\AA$ ) and the average sound velocity $\mathrm{v}_{\mathrm{m}}$ (in $\mathrm{km} / \mathrm{s}$ ) using the following equation [26]:

$\theta_{\mathrm{D}} \approx(595.467) \mathrm{V}_{\mathrm{m}} / \mathrm{a}(10)$

The calculated values of $\mathrm{vl}, \mathrm{vt}, \mathrm{vm}$ and $\theta_{\mathrm{D}}$ of BP compound with B1 structure are found at around 11.684, $8.1948 .895 \mathrm{~km} / \mathrm{s}$, and $1254 \mathrm{~K}$, respectively. The calculated values of $\mathrm{vl}, \mathrm{vt}_{\mathrm{t}} \mathrm{\textrm {V }}$ and $\theta_{\mathrm{D}}$ are slightly higher than the values $10.965,7.579,8.244 \mathrm{~km} / \mathrm{s}$, and $1147 \mathrm{~K}$, respectively reported in our previous work [13]. In the cubic system, a semi-empirical expression related the Debye temperature and the elastic constants of crystal has been established by Blackman [35], it is given as follow:

$$
\theta_{D}^{3}=\frac{3.15}{8 \pi}\left(\frac{h}{k_{B}}\right)^{3}\left(\frac{n}{\rho^{3 / 2} v_{a}}\right)\left(C_{11}-C_{12}\right)^{1 / 2}\left(C_{11}-C_{12}+2 C_{44}\right)^{1 / 2}\left(C_{44}\right)^{1 / 2}(11)
$$

Where: $\mathrm{k}_{\mathrm{B}}$ is the Boltzmann constant $\left(\mathrm{k}_{\mathrm{B}}=1.38062 \times 10^{-23} \mathrm{~J} . \mathrm{K}^{-1}\right)$, $\mathrm{h}$ is the Planck's constant $\left(\mathrm{h}=6.62617 \times 10^{-34} \mathrm{~J} . \mathrm{s}\right), \mathrm{n}$ is the number of atoms in unit cell of volume $\mathrm{va}$ and $\rho$ is the crystal density. The calculated values of the Debye temperature of BP compound with B1 structure was found at around $1314.4 \mathrm{~K}$. This value of $\theta_{\mathrm{D}}$ is slightly higher than the values 1254 and $1147 \mathrm{~K}$ obtained from Eq. (10) and reported in our previous work [13], respectively.

Another empirical formula was applied successfully by Siethoff [36], it is given by the following expression:

$$
\theta_{D}=C_{s} n^{-1 / 6}\left(a M^{-1}\left[C_{44}\left(C_{44}\left(C_{11}-C_{12}\right) / 2\right)^{1 / 2}\left(C_{11}-C_{12}+C_{44}\right) / 3\right]^{1 / 3}\right)^{1 / 2}(12
$$

Here $\mathrm{Cs}$ is a constant $\left(\mathrm{Cs}=(26.05 \pm 0.81) \mathrm{K}\left(\mathrm{m} \mathrm{kg} \mathrm{N}^{-1}\right)^{1 / 2}\right), \mathrm{n}$ is the number of atoms in the unit cell, a is the lattice parameter, and $\mathrm{M}$ is the atomic weight of the element (for compounds, $\mathrm{M}$ is the weighted arithmetical average of the masses of the species).

Based on the formula of Eq. (12), the calculated value of $\Theta_{\mathrm{D}}$ was estimated at about $1310.2 \mathrm{~K}$, it is excellent agreement with the value $1314.4 \mathrm{~K}$ obtained from Blackman's formula [35], the deviation between these two values is only around $0.32 \%$. Except the results reported in our previous work [13], to the best of my knowledge, there are no other data available in the literature on the sound velocity and the Debye temperature for BP compound with B1 structure.

\section{Conclusion}

In the present work, we employed the PW-PP approach in the framework of the DFT and the DFPT to investigate the structural parameters and elastic constants of cubic rock-salt BP compound. The structural parameters values obtained in this work are in general agreed well with other theoretical data of the literature. The isotropic shear modulus, the elastic anisotropy factor, the Zener factor, the inverted Pugh's ratio, the Cauchy pressure, the Young's modulus, the Poisson's ratio, the Vickers hardness, the elastic wave speeds as well as the Debye temperature $\theta_{\mathrm{D}}$ of our material of interest were also predicted. The calculated elastic anisotropy factor and the Zener anisotropy factor indicate that (B1) BP compound is elastically anisotropic. The values of the ratio B/G and the Cauchy pressure show a brittle manner for cubic rock-salt BP compound. The values of the elastic wave speeds and the Debye temperature obtained in this work are slightly higher the values reported in our previous work [13] using the GGA. 


\section{References}

[1] A. Bouhemadou, R. Khenata, M. Kharoubi, T. Seddik, Ali H. Reshak, and Y. Al-Douri, " FP-APW + lo calculations of the elastic properties in zinc-blende III-P compounds under pressure effects ", Computational Materials Science, Vol. 45, No. 2, (2009), pp. 474-479. https://doi.org/10.1016/j.commatsci.2008.11.013.

[2] F. El Haj Hassan, H. Akbarzadeh, and M. Zoaeter, "Structural properties of boron compounds at high pressure ", Journal of Physics: Condensed Matter, Vol. 4, No. 3, (2004), pp. 293-301. https://doi.org/10.1088/0953-8984/16/3/009.

[3] S. Daoud, N. Bioud, and N. Lebga, " Elastic, optoelectronic and thermal properties of boron phosphide ", Journal of Nano- and Electronic Physics,Vol. 5, No. 4, (2013), pp. 04061 (6 pages). https://jnep.sumdu.edu.ua/download/numbers/2013/4/articles/jnep_2013_V5_04061.pdf.

[4] H. Meradji, S. Drablia, S. Ghemid, H. Belkhir, B. Bouhafs, and A. Tadjer, " First-principles elastic constants and electronic structure of BP, BAs, and BSb ", Physica Status Solidi B, Vol. 241, No. 13, (2004) pp. 2881-2885. https://doi.org/10.1002/pssb.200302064.

[5] O. Arbouche, B. Belgoumène, B. Soudini, Y. Azzaz, H. Bendaoud, and K. Amara, " First-principles study on structural properties and phase stability of III-phosphide (BP, GaP, AlP and InP) ", Computational Materials Science, Vol. 47, No. 3, (2010), pp. 685-692. https://doi.org/10.1016/j.commatsci.2009.10.009.

[6] S. Daoud, K. Loucif, N. Bioud, N. Lebga, and L. Belagraa, " Effect of hydrostatic pressure on the structural, elastic and electronic properties of (B3) boron phosphide ", Pramana Journal of Physics, Vol. 79, No. 1, (2012), pp. 95-106. https://doi.org/10.1007/s12043-012-0283-8.

[7] M. Ustundag, M. Aslan, and Battal G. Yalcin, "The first-principles study on physical properties and phase stability of Boron-V (BN, BP, BAs, BSb and BBi) compounds", Computational Materials Science, Vol.81, , No. 1, (2014), pp. 471-477.https://doi.org/10.1016/j.commatsci.2013.08.056.

[8] P. Kocinski and M. Zbroszczyk, " Calculated structural and electronic properties of boron phosphide under pressure ", Semiconductor Science and Technology, Vol. 10, No. 11, (1995), pp. 1452-1457.https://doi.org/10.1088/0268-1242/10/11/004.

[9] D. Varshney, G. Joshi, M. Varshney, and S. Shriya, "Pressure induced mechanical properties of boron based pnictides", Solid State Sciences, Vol. 12, (2010), pp. 864-872. https://doi.org/10.1016/j.solidstatesciences.2010.02.003.

[10] W. Wettling and J. Windscheif, "Elastic constants and refractive index of boron phosphide", Solid State Communications, Vol.50, No. 1, (1984), pp. 33-34. https://doi.org/10.1016/0038-1098(84)90053-X.

[11] S. Daoud, N. Bioud, and N. Lebga, " Mechanical, piezoelectric and some thermal properties of (B3) BP under pressure ", Journal of Central South University, Vol. 21, No. 1, (2014), pp. 58-64. https://doi.org/10.1007/s11771-014-2394-4.

[12] S. Daoud, N. Bioud, N. Lebgaa, and R. Mezouar "Optoelectronic and thermal properties of boron- bismuth compound", International Journal of Physical Research, Vol. 2, No. 2, (2014), pp. 27-31. http://www.sciencepubco.com/index.php/IJPR/article/view/2760. https://doi.org/10.14419/ijpr.v2i2.2760.

[13] S. Daoud, "EOS parameters and elastic properties of cubic rock-salt BP ", International Journal of Physical Research, Vol. 7, No. 1, (2019), pp. 710. https://www.sciencepubco.com/index.php/IJPR/article/view/25863.

[14] Y. Wen, L. Wang, H. Liu, and L. Song, "Ab-initio study of the elastic and mechanical properties of B19 TiAl ", Crystals, Vol. 7, No. 2, (2017), pp. 39 (11 pages). https://doi.org/10.3390/cryst7020039.

[15] S. F. Pugh, "XCII. Relations between the elastic moduli and the plastic properties of polycrystalline pure metals", The London, Edinburgh, and Dublin Philosophical Magazine and Journal of Science, Vol.45, No. 367, (1954), pp. 823-843.https://doi.org/10.1080/14786440808520496.

[16] The ABINIT code is a common project of the Université Catholique de Louvain, Corning Incorporated, and other contributors. http://www.abinit.org.

[17] N. Troullier and J. L. Martins, "Efficient pseudopotentials for plane-wave calculations ", Physical Review B, Vol.43, No. 3, (1991), pp. 1993-2002. https://doi.org/10.1103/PhysRevB.43.1993.

[18] M. Fuchs and M. Scheffler, "Ab initio pseudopotentials for electronic structure calculations of poly-atomic systems using density-functional theory", Computer Physics Communications, Vol.119, No. 1, (1999), pp. 67-98. https://doi.org/10.1016/S0010-4655(98)00201-X.

[19] J. P. Perdewand Y. Wang, "Accurate and simple analytic representation of the electron-gas correlation energy", Physical Review B, Vol.45, No. 23, (1992) 13244-13249. https://doi.org/10.1103/PhysRevB.45.13244.

[20] H.J. Monkhorst and J.D. Pack, "Special points for Brillouin-zone integrations", Physical Review B, Vol. 13, No. 12, (1976), pp.5188 - 5192. https://doi.org/10.1103/PhysRevB.13.5188.

[21] S. B. Zhang and M. L. Cohen, "High-pressure phases of III-V zinc-blende semiconductors", Physical Review B, Vol. 35, No. 14, (1987), pp. 76047610. http://journals.aps.org/prb/abstract/10.1103/PhysRevB.35.7604.https://doi.org/10.1103/PhysRevB.35.7604

[22] T. Özer, "Study of first principles on anisotropy and elastic constants of $\mathrm{YAl}_{3}$ compound", Canadian Journal of Physics, Vol. 98, No. 4, (2020), pp 357-363.https://doi.org/10.1139/cjp-2018-0448.

[23] Y.O. Ciftci and E. Ateser, "A theoretical study of pressure-induced effects on phase transition and elastic properties of AsTh compound", Journal of Electronic Materials Vol. 49, No. 3, (2020), pp. 2086-2094. https://doi.org/10.1007/s11664-019-07891-3.

[24] N. Bioud, X.W. Sun, N. Bouarissa, and S. Daoud, "Elastic constants and related properties of compressed rocksalt CuX (X = Cl, Br): Ab-initio study", Zeitschrift Für Naturforsch A, Vol. 73, No. 8, (2018), pp. 767-773. https://doi.org/10.1515/zna-2018-0120.

[25] N. Lebga, S. Daoud, X-W. Sun, N. Bioud, and A. Latreche, "Mechanical and thermophysical properties of cubic rock-salt AlN under high pressure ", Journal of Electronic Materials, Vol. 47, No. 7, (2018), pp. 3430-3439.https://doi.org/10.1007/s11664-018-6169-x.

[26] S. Daoud, "Mechanical and piezoelectric properties, sound velocity and Debye temperature of thallium-phosphide under pressure", International Journal of Advanced Research in Physical Science, Vol. 1, No. 6, (2014), pp. 1-11. www.arcjournals.org/pdfs/ijarps/v1i6/1.pdf.

[27] S. Daoud, N. Bouarissa, A. Benmakhlouf, and O. Allaoui, "High-pressure effect on elastic constants and their related properties of MgCa intermetallic compound", Physica Status Solidi B, Vol. 257, (2020), pp. 1900537 (10 pages).https://doi.org/10.1002/pssb.201900537.

[28] S. Stølen, T. Grande, and N. L. Allan, "Chemical thermodynamics of materials", John Wiley \& Sons Ltd, England, (2004). ISBN 0-471-49230-2.

[29] S. Adachi, "Properties of group-IV, III-V and II-VI semiconductors", John Wiley \& Sons Ltd, England, (2005). ISBN 0-470-090324.https://doi.org/10.1002/0470090340.

[30] Q. Li, X. Zhang, H. Liu, H. Wang, M. Zhang, Q. Li, and Y. Ma, " Structural and mechanical properties of platinum carbide ", Inorganic Chemistry Vol. 53, No. 11, (2014), pp. 5797-5802. https://doi.org/10.1021/ic5006133.

[31] S. Daoud, K. Loucif, N. Bioud, and N. Lebga, "First-principles study of structural, elastic and mechanical properties of zinc-blende boron nitride (B3-BN) ", Acta Physica Polonica A, Vol. 122, No. 1, (2012), pp. 109-115. https://doi.org/10.12693/APhysPolA.122.109.

[32] A. Bouhemadou, D. Allali, S. Bin-Omran, E. Muhammad Abud AlSafi, R. Khenata, and Y. Al-Douri, "Elastic and thermodynamic properties of the $\mathrm{SiB} 2 \mathrm{O} 4$ (B=Mg, Zn and Cd) cubic spinels: An ab initio FP-LAPW study", Materials Science in Semiconductor Processing, Vol. 38, No. 10, (2015), pp. 192-202. https://doi.org/10.1016/j.mssp.2015.04.021.

[33] V. V. Brazhkin, A. G. Lyapin, and R. J. Hemley, " Harder than diamond: Dreams and reality", Philosophical Magazine A, Vol.82, No. 2, (2002), pp. 231-253. https://doi.org/10.1080/01418610208239596.

[34] X. H. Wang, H.W. Wang, Z. J. Wei, and C. M. Zou, "Al ${ }_{3}$ Ni alloy synthesized at high pressures and its Debye temperature", Journal of Alloys and Compounds, Vol. 774, No. 2, (2019), pp. 364-369. https://doi.org/10.1016/j.jallcom.2018.09.331.

[35] M. Blackman, "On the calculation of characteristic temperatures from the elastic constants", Philosophical Magazine, Vol.42, No. 335, (1951), pp. 1441-1442. https://doi.org/10.1080/14786445108560963.

[36] H. Siethoff, "Debye temperature, self-diffusion and elastic constants of intermetallic compounds", Intermetallics, Vol.5, No. 8, (1997), pp. 625-632. https://doi.org/10.1016/S0966-9795(97)00037-X. 